\title{
Spatial and temporal heterogeneity of the cod spawning environment in the Bornholm Basin, Baltic Sea
}

\author{
H.-H. Hinrichsen ${ }^{1, *}$, R. Voss ${ }^{1}$, K. Wieland ${ }^{2}$, F. Köster ${ }^{3}$, K. H. Andersen ${ }^{3}$, \\ P. Margonski ${ }^{4}$ \\ ${ }^{1}$ Leibniz Institute of Marine Sciences, Düsternbrooker Weg 20, 24105 Kiel, Germany \\ ${ }^{2}$ Greenland Institute of Natural Resources, PO Box 570, 3900 Nuuk, Greenland \\ ${ }^{3}$ Danish Institute of Fisheries Research, Charlottenlund Castle, 2920 Charlottenlund, Denmark \\ ${ }^{4}$ Sea Fisheries Institute, Kollataja 1, 81-332 Gdynia, Poland
}

\begin{abstract}
The present study quantifies the spatial heterogeneity of the environmental conditions associated with successful spawning by cod Gadus morhua in the Bornholm Basin. Quarterly means from 1989 to 2003 of the thickness of reproductive volume that enabled egg survival indicate that most favourable spawning conditions were located in the central area, inside the $80 \mathrm{~m}$ isobath. On average, spatial patterns were similar in the second and third quarters, but with overall lower thicknesses of reproductive volume and less horizontal extension of conditions suitable for egg survival in the third quarter. The observed basin-wide variation in thickness of reproductive volume and oxygen content inside this volume can result in marked horizontal differences in oxygen-related egg mortality, especially during stagnation years. The spawning habitat selected by adult Baltic cod in the Bornholm Basin was characterised by comparing data on egg abundance with environmental variables measured concurrently with egg collection. A clear preference for spawning at locations in the deep basin is evident after both inflow events, as well as for stagnation periods. In consequence, the closed area for fishing implemented in the Bornholm Basin during the main spawning periods from 1995 to 2003, although located in the northern centre of the basin, did not necessarily ensure undisturbed spawning in stagnation years.
\end{abstract}

KEY WORDS: Baltic cod · Environmental conditions $\cdot$ Reproductive volume $\cdot$ Egg survival probability

\section{INTRODUCTION}

As typical for estuaries, Baltic Sea marine and freshwater organisms are found in a regional succession with different species-specific ranges of distribution. Depending on their specific adaptation and tolerance for hydrographic property levels (e.g. temperature, salinity and oxygen), many species approach the limit of their general area of distribution in the Baltic Sea and may thus also show an increased vulnerability and stock size variability related to changes in the environmental conditions.

The continuous freshwater runoff from a number of large rivers along the Baltic coast, accompanied by irregular events of saline water inflows, causes a permanent stratification of the Baltic Sea water body as far north as the Aaland Sea (Elmgren 1984). The effective separation of surface- and deep-water caused by differences in density hampers mixing and thus transport of oxygen from the upper layers down to the deep areas. As a result, oxygen depletion is a common phenomenon over large areas in the deep basins, which affects the reproduction of cod Gadus morhua by limiting the survival of eggs (Nissling et al. 1994, Wieland et al. 1994). In contrast to those from other cod stocks, these cod eggs from the eastern Baltic cod stock do not float in the surface waters, but neutral buoyancy and peak abundance occurs in the region of the halocline, 
with some quantities occurring in the more saline deep layer (salinity > 11 psu; Kändler 1949, Müller \& Pommeranz 1984, Wieland 1995). These conditions are met exclusively at locations with water depth deeper than $60 \mathrm{~m}$ (Wieland et al. 1994). Cod eggs from the eastern Baltic cod stock are regularly exposed to water with less than the critical amount of oxygen necessary for successful egg development (oxygen $>2 \mathrm{ml} \mathrm{l}^{-1}$; Nissling \& Westin 1991, Bagge et al. 1994).

A recently developed oxygen-related survival index (Köster et al. 2005) incorporates not only the volume for potentially sustaining egg development, but provides a measure of the oxygen conditions within the salinity range over which cod eggs are neutrally buoyant.

Temperature-controlled laboratory experiments have been performed to describe the influence of oxygen concentration on the proportion of viable hatch in relation to the surviving fraction under normoxic conditions (Rohlf 1999). These experiments confirmed that oxygen concentrations above the threshold level of $2 \mathrm{ml} \mathrm{l}^{-1}$ used to define the Baltic cod reproductive volume (RV) have a strongly positive impact on egg survival. A sigmoidal oxygen-egg survival relationship (Köster et al. 2005) can be applied to estimate the fraction of the egg production that will probably survive during the spawning season to the larval stage.

Compared with other stocks in the North Atlantic, the eastern Baltic cod stock has a lengthy spawning period (ICES 2005). This behavioural pattern has been explained as an adaptation to the variable and sometimes critical environmental conditions in the Baltic Sea (e.g. MacKenzie et al. 1996). In the 1970s and 1980s, the time of peak spawning identified on the basis of egg abundance estimates in the Bornholm Basin occurred between the end of April and mid-June (Wieland et al. 2000a). From the early 1990s onwards, the time of highest egg production has gradually changed to later summer months. This observed shift in the main spawning time may have been caused by (1) removal of early spawners by the fishery, mainly directed at pre-spawning and early spawning concentrations (ICES 1999), (2) a coupling of maturation processes at ambient temperature, as reported by Wieland et al. (2000a), and (3) a decline of the calanoid copepod Pseudocalanus acuspes, which provide a food source, especially for early spawned cod larvae (Hinrichsen et al. 2002a); as a result, only late spawners have a chance to successfully reproduce.

Historically, there have been 3 main spawning areas for the central Baltic cod stock: the Bornholm Basin, the Gdansk Deep and the Gotland Basin (Fig. 1). Recent analyses of spatial and temporal heterogeneity of the RV have recognised that conditions for successful cod egg development are most likely to be found in the Bornholm Basin (MacKenzie et al. 2000). However, exceptions to this broad pattern do occur. During the longest recorded period without a major Baltic inflow of North Sea water (1977 to 1993), the RV in the Bornholm Basin reduced dramatically. On the other hand, oxygen renewal events (e.g. inflows) can rapidly and significantly improve conditions in all basins (Matthäus \& Lass 1995). However, the most recent years showed that the direct effect of a single water inflow is limited because (1) unfavourable hydrographic conditions may already return in the following year, i.e. the improvement for cod is restricted to 1 spawning season only, or (2) inflowing oxygenated water replaces only the lower sections of the bottom water, resulting in an intermediate water layer with sufficient salinity to keep cod eggs floating, but not enough oxygen to sustain their development. The hydrography in the Bornholm Basin during stagnation periods can be characterised by a high variability in oxygen concentration in bottom and halocline waters caused by regular smaller to medium sized (nonmajor) inflow events. Inflows mainly occur during winter months; thus, inflow situations generally cause low bottom water temperatures because the inflowing water originates from surface areas in the western Baltic during winter (Hinrichsen et al. 2002b).

The present study describes the spatial environmental heterogeneity of the Baltic cod spawning habitat in the Bornholm Basin. We have calculated stationbased, averaged environmental variables describing the spawning habitat quality in order to identify longer term spatial differences. We present horizontal property fields associated with stagnation periods contrasted with more favourable spawning conditions strongly affected by inflow events. Our approaches are empirically based and involve egg abundance data in addition to environmental variables. Finally, the approach attempts to characterise spatial and temporal variability in an eastern Baltic cod spawning area and the habitat-related environmental parameters of the area from 1989 to 2003, in light of the applicability and/or effectiveness of closed areas for fisheries to ensure undisturbed spawning as enforced until 2003 (ICES 2004).

\section{MATERIALS AND METHODS}

Horizontal distribution patterns. The hydrographic and ichthyoplankton data set consists of measurements from 51 cruises carried out in the Bornholm Basin between May 1989 and November 2003. The station grid represents the Bornholm Basin enclosed by the $60 \mathrm{~m}$ isobath (Fig. 1). This station grid encompasses the historical distribution of peak egg and larval abundance of Baltic cod Gadus morhua in the Bornholm 


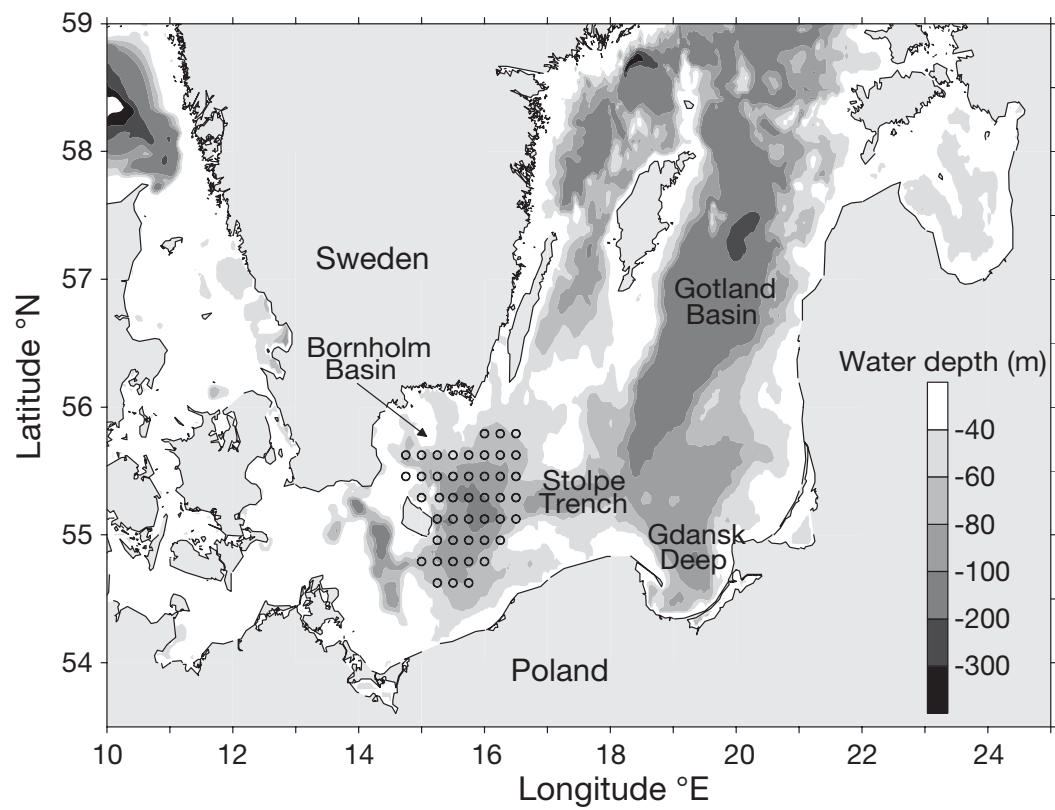

Fig. 1. Baltic Sea, with standard station grid in the Bornholm Basin (45 stations)

surements, i.e. a weighted sum of all observations. It was assumed that error due to measurement errors and smallscale noise amounted to $15 \%$ of the total variance of the fields. Only areas in which the expected root mean square (rms) error in the interpolation was $<50 \%$ of the standard deviations of the fields were considered. As most of the surveys were designed to produce quasi-synoptic maps of physical and biological properties, a unit array configuration with a horizontal resolution of $\mathrm{d} x=\mathrm{d} y=5 \mathrm{~km}$ was provided based on the standard station grid, whereby each of the grid points is representative of the analysed properties centred around it. Objective analysis provided a smoothed version of the original measurements, with a tendency to underestimate the true field because of specific assumptions involved in our treatment of the measurement noise and small-

Basin (Wieland 1995). The earliest cruises covered only 21 to 36 stations, but since 1994, a total of 45 standard stations has been covered with a horizontal resolution between 8 and 10 nautical miles. The hydrographic survey data were used to calculate the Baltic cod spawning conditions. Physical parameters (conductivity, temperature and oxygen) of the water column were usually measured with $\mathrm{CTD} / \mathrm{O}_{2}$ systems, while the horizontal distribution of cod eggs was based on Bongo hauls (oblique hauls, surface to $5 \mathrm{~m}$ from bottom; 300 and $500 \mu \mathrm{m}$ mesh size; $60 \mathrm{~cm}$ diameter), a method suitable for sampling eggs and larvae up to $10 \mathrm{~mm}$ length.

Based on the hydrographic standard station grids, we calculated quarterly means of cod spawning conditions in the Bornholm Basin in terms of spawning layer thickness. Horizontal maps were constructed by interpolating observed data onto a regular grid by objective analysis (Bretherton et al. 1976). An Gaussian isotropic covariance function:

$$
f(r)=\sigma^{2} \exp \left(-r^{2} / R^{2}\right)
$$

was chosen with $R$ as the autocorrelation scale, $\sigma$ the variance and $r$ the distance between data points. A spatial autocorrelation function of the fields was derived from the isotropic covariance function with the parameter $R$ determined from the fit of this function to the raw covariances of the field observations. Objective analysis has the advantage that it can use statistical results and assumptions concerning measurement noise and small-scale errors inferred from the observed data. Thus, at every single data point, an estimate can be given that depends linearly on the total number of mea- scale signals unresolved by the observation array. Error estimates were based only on the statistics of the field, the noise level and on the locations of the observation points, and not the measurements themselves.

Estimates of RV (salinity $>11 \mathrm{psu}$, oxygen $>2 \mathrm{ml} \mathrm{l}^{-1}$, temperature $>1.5^{\circ} \mathrm{C}$ ) by subsequent horizontal integration indicate the volume of water that meets minimum requirements for successful cod egg development (Nissling \& Westin 1991, Plikshs et al. 1993). However, these estimates do not directly consider the environmental conditions inside the water volume that principally sustains egg development. Therefore, oxygenrelated cod egg survival (Köster et al. 2005) has been considered in our analyses as an additional habitatrelated environmental parameter for characterising the spatial variability of eastern Baltic cod spawning areas.

Selection of spawning habitat and habitat-related environmental parameters. To assess and identify the preferred ranges of Baltic cod spawning habitat and the environmental variables within the spawning habitat, quotient curves derived from egg abundance data and individual environmental variables were constructed. Each environmental variable was assigned a number of environmental categories, and the ratio of the percentage frequency of occurrence of each category and the percentage of total number of eggs within each category c was calculated:

$$
Q_{\mathrm{C}}=\% \text { eggs }_{\mathrm{C}} / \% \text { environmental variable }{ }_{\mathrm{C}}
$$

This analysis was based on the minimum number of hydrographic and ichthyoplankton stations carried out during the earliest cruises at the end of the 1980s and 


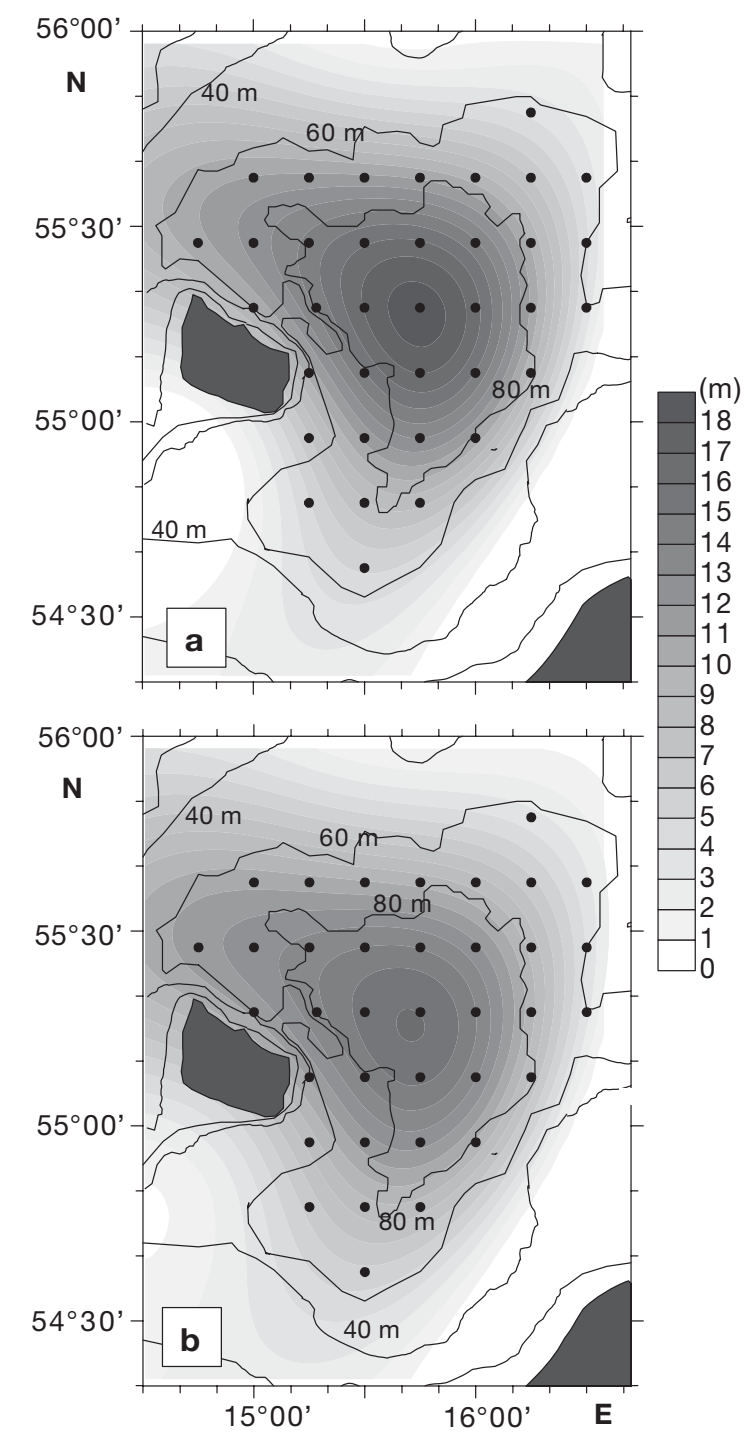

Fig. 2. Gadus morhua. Mean horizontal distribution of the thickness of Baltic cod reproductive volume $(\mathrm{m})$ in the

Bornholm Basin: (a) second quarter and (b) third quarter

the beginning of the 1990s. Between 18 and 28 categories of each environmental variable were chosen to ensure that the maximum occurrence per category did not exceed 15 to $20 \%$ of the measurements. Quotient values $>1$ were considered positively chosen categories and those $<1$ indicate avoidance of those environmental categories for spawning (van der Lingen et al. 2001). This approach was used to examine relationships between recently spawned cod eggs (Stage Ia) and environmental variables representing the size, location and quality of the cod spawning habitat. The locations of the earliest egg stage may vary based on the distribution of the adults that are spawning, but the duration of the earliest egg stage is short (ca. 2 to $3 \mathrm{~d}$; Wieland et al. 1994), and drift velocities at the level of

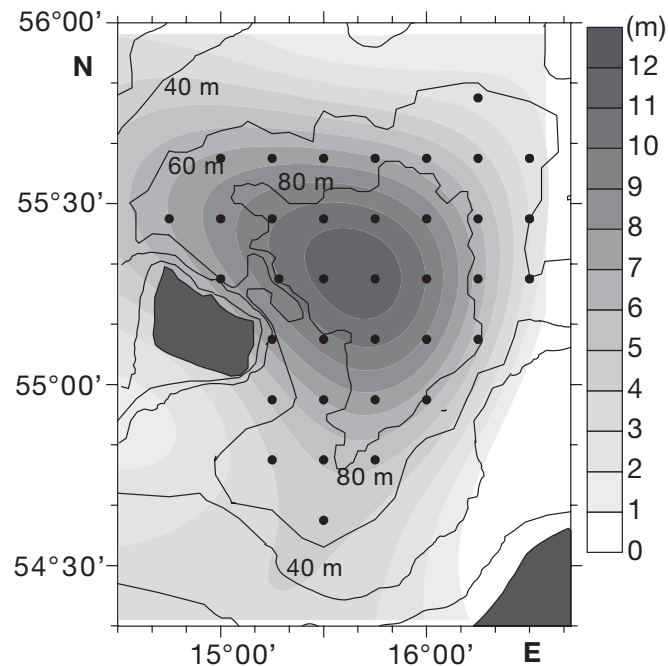

Fig. 3. Gadus morhua. Variation in mean thickness of Baltic cod reproductive volume in the Bornholm Basin (standard deviation; $\mathrm{m}$ )

cod egg occurrence are low (a few km per day; Krauss \& Brügge 1991). Thus, the horizontal distribution of newly spawned eggs provided a measure for the habitat selection of adult cod. For statistical evaluation, the adapted $R$ library 'Shachar' (developed by M. Bernal, Instituto Español de Oceanografia, Centro Oceanográfico de Malaga, Spain) was applied to include a randomisation test, which estimates the $95 \%$ confidence limits for rejecting the null hypothesis, i.e. that the observed quotient within a particular bin of an environmental variable was obtained by pure chance alone.

\section{RESULTS}

\section{Horizontal distribution patterns of spawning conditions and egg survival probability}

Quarterly means from 1989 to 2003 of the RV thickness that enabled egg survival indicate that most favourable spawning conditions for Gadus morhua were located in the central deep area of the Bornholm Basin, i.e. inside the $80 \mathrm{~m}$ isobath. On average, spatial patterns were similar in the second and third quarters (Fig. 2), but with overall lower RV thicknesses and less horizontal extension of conditions suitable for egg survival in the third quarter. As depicted in Fig. 3, the highest variation in RV thickness also occurred in the centre of the Bornholm Basin, with a tendency toward higher variability in the northern part. The spatial autocorrelation of mean and standard deviation of the $\mathrm{RV}$ varied between 51 and $63 \mathrm{~km}$ in the $x$-direction and between 33 and $40 \mathrm{~km}$ in the $y$-direction. 

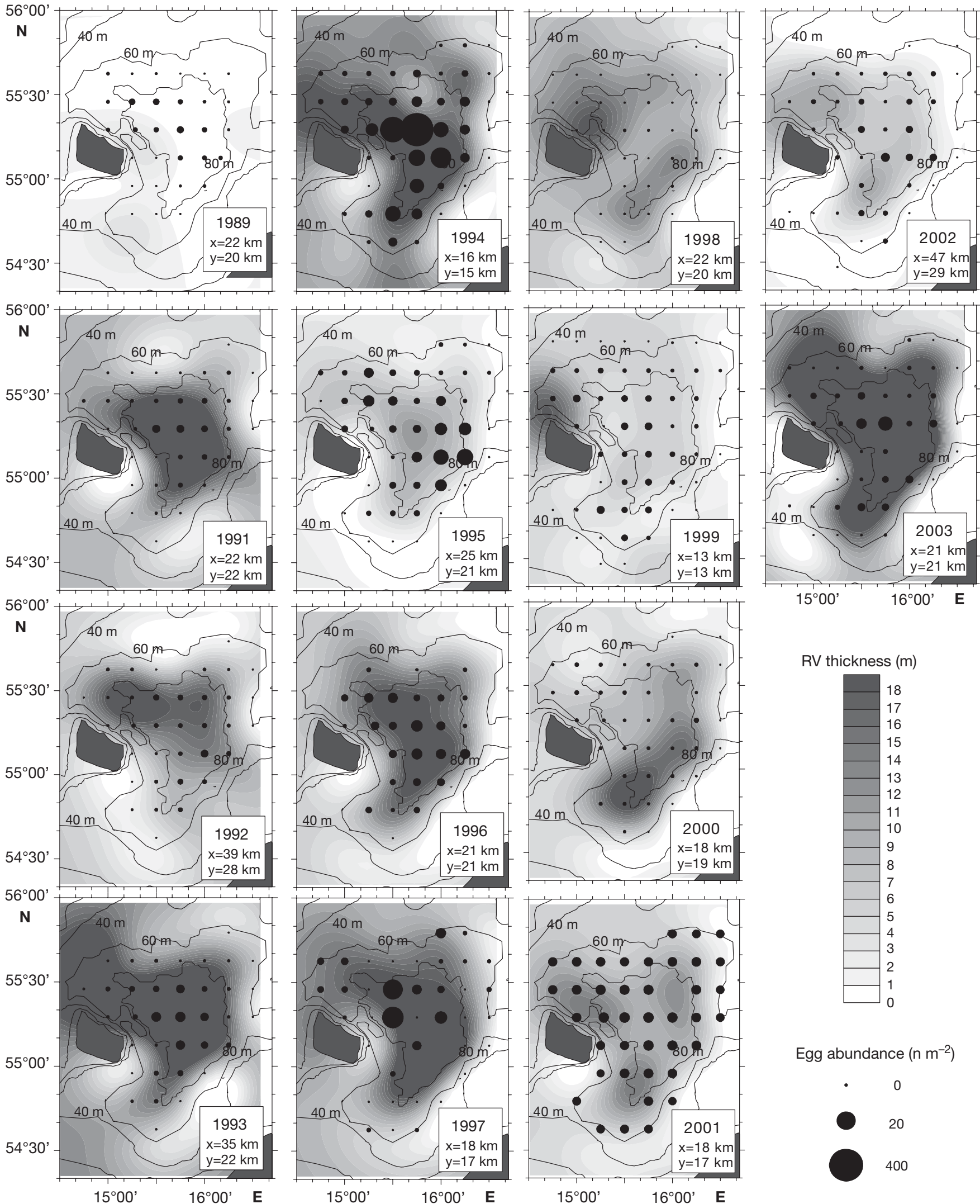

RV thickness $(\mathrm{m})$

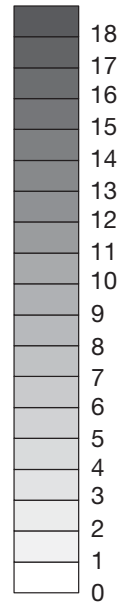

Egg abundance $\left(\mathrm{n} \mathrm{m}^{-2}\right)$

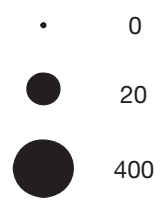

Fig. 4. Gadus morhua. Thickness of Baltic cod reproductive volume (RV, m) and Egg Stage Ia distribution in the Bornholm Basin (1989 to 2003) 


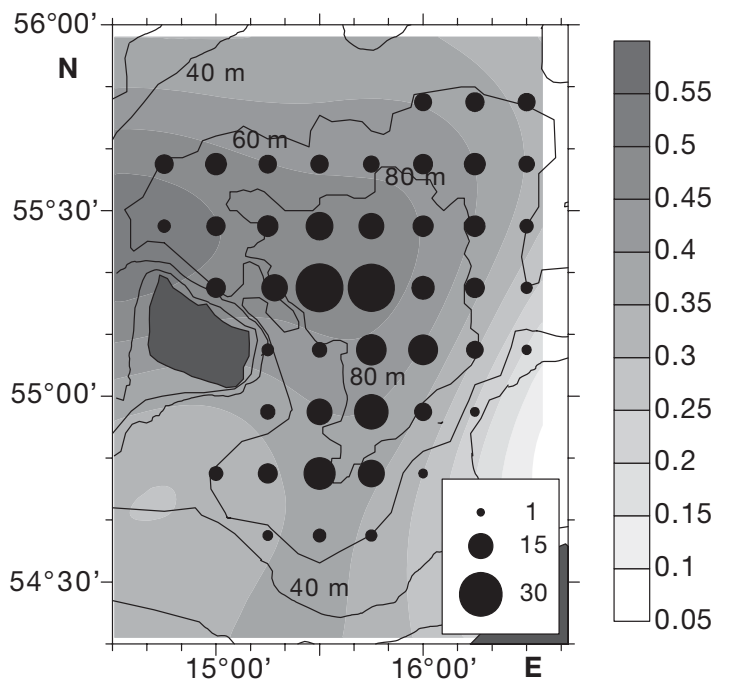

Fig. 5. Gadus morhua. Greys: mean survival probability; dots: mean Baltic cod Egg Stage Ia distribution in the Bornholm Basin (1989 to 2003; $\mathrm{n} \mathrm{m}^{-2}$ )

The spatial distribution of early cod eggs in the Bornholm Basin during peak spawning shows the highest abundances in the area enclosed by the $80 \mathrm{~m}$ isobath, considerably lower abundance in intermediate depths ( 60 to $80 \mathrm{~m}$ ) and, for the most part, an absence of eggs in areas $<60 \mathrm{~m}$ (Fig. 4). This egg distribution does not necessarily match the best environmental conditions. Especially in stagnation years (1989, 1995, 2001 and 2002), the highest abundances of cod eggs were found outside the best spawning conditions. Pronounced RVs outside the central basin were not utilised for intensive spawning. The spatial autocorrelation scales are highly variable interannually and much smaller than the mean distribution of RV (13 to $47 \mathrm{~km}$ in the $x$ - and 13 to $29 \mathrm{~km}$ in the $y$-direction).

Cod egg survival probability in the RV in terms of the oxygen concentrations experienced by the cod eggs is presented in Fig. 5. On average, the highest probability of cod egg survival occurred in the northwestern area between the island of Bornholm and the Swedish coast. Furthermore, high egg survival probability occurred in the northern area of the central basin. The south central part of the basin and areas with water depths shallower than $80 \mathrm{~m}$ showed significantly lower survival probability. Spatial autocorrelation was similar to RV thickness with $46 \mathrm{~km}$ in the $x$ - and $29 \mathrm{~km}$ in the $y$-direction. The observed basin-wide variation in RV thickness and oxygen content inside the RV can result in marked horizontal differences in oxygenrelated mortality, especially during stagnation years. The mean distribution of the youngest egg stage (Ia) during the main spawning periods from 1989 to 2003 suggests that the main spawning effort took place in the centre and to a minor extent in the southeast Born- holm Basin, which demonstrates a mismatch of average spawning activity and optimal spawning conditions in terms of oxygen content in the RV.

\section{RV characteristics during stagnation and post-inflow periods}

During stagnation years the RV thickness was lower than mean conditions, while the horizontal variability in RV thickness was more pronounced (Fig. 5). On average, the RV had a thickness $<15 \mathrm{~m}$ throughout most of the central basin. During inflow and postinflow years $(1993,1994,2003)$, vertical extension was greater $(>20 \mathrm{~m}$ ) and lower thicknesses of the spawning volume were only recorded at the central basin's outer edge. However, in 1994, the favourable oxygen conditions did not persist throughout the year and the RV decreased strongly from spring 1994 to summer 1995.

\section{Selection of spawning habitat and habitat-related environmental parameters}

The Stage Ia cod egg distribution during both stagnation periods and after inflow events indicates that spawning mainly occurred within the deep basin of the Bornholm Basin at stations with water depths deeper than $80 \mathrm{~m}$ (Fig. 6). During stagnation years there was a significant preference for stations where RV extended vertically to the 25 and 29 m levels, whereas during inflow years there were 2 less pronounced, significantly positive categories: 1 mid-range and 1 high category. Note that during inflow years, the mid-range level equaled the highest level during stagnation periods and was mainly found at stations with water depths deeper than $80 \mathrm{~m}$. Generally, high concentrations of newly spawned eggs were found in the central basin after saline- and oxygen-rich inflows and lower abundances occurred at the edges of the basin, accompanied by decreasing values of RV thickness. During stagnation periods, the highest concentrations of the youngest egg stage were also found in the centre of the basin, but the distribution was more widely spread and overall egg abundance was lower than in post-inflow years. No clear significant preference for spawning in welloxygenated water masses was detectable during either stagnation or inflow years.

\section{Seasonal development of reproductive volumes and egg survival probability}

Hydrographic data collected in the months following the most recent major Baltic inflow in early 2003 illus- 

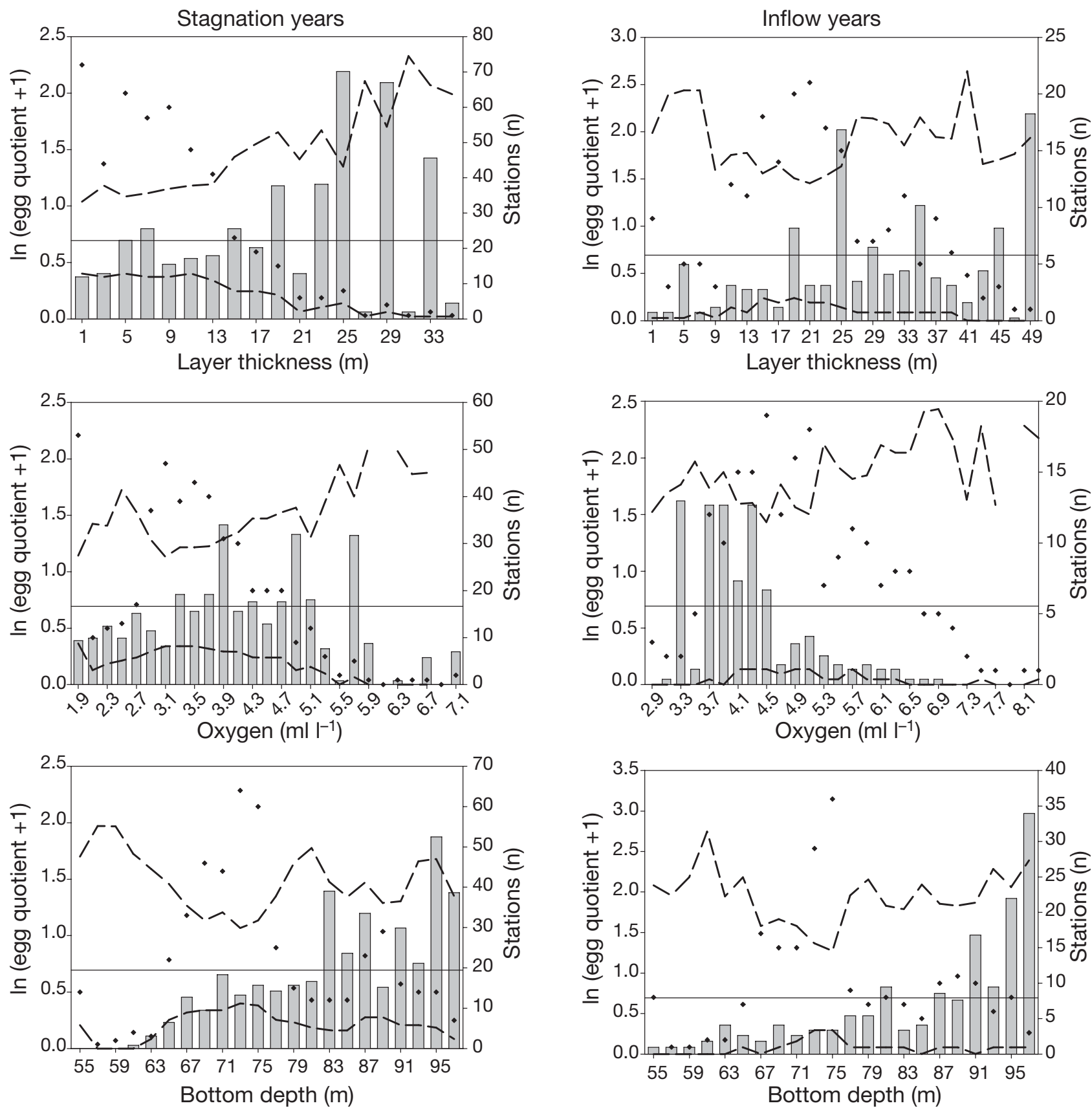

Fig. 6. Quotient rule analysis: stagnation years and inflow years 1993, 1994 and 2003. Bars: quotient curves; dots: number of observations; dashed lines: $95 \%$ confidence interval. Upper panels: thickness of reproductive volume; middle panels: $\mathrm{O}_{2}-$ oxygen content in Baltic cod Gadus morhua reproductive volume; lower panels: bottom depth. Horizontal line: quotient values of 1 on a log-scale

trate the role that oxygen consumption can have on the seasonal development of the RV. The data indicate that oxygen concentrations near and below the halocline quickly decreased from March to August (Fig. 7). Due to biological processes, the oxygen content at the bottom decreased from almost 6 to $3 \mathrm{ml} \mathrm{l}^{-1}$. In contrast, oxygen depletion in the upper halocline (50 to $70 \mathrm{~m}$ ) and above the halocline was mainly due to lateral advection of water masses (upper halocline) as well as temperature increase and mixing processes in the upper water layer. Although oxygen consumption in the volume of water suitable for cod egg development was significant, the RV only decreased from $217 \mathrm{~km}^{3}$ in March to $200 \mathrm{~km}^{3}$ in August 2003. However, the average oxygen-related egg survival probability decreased on average from $78 \%$ in March to $23 \%$ in August. 


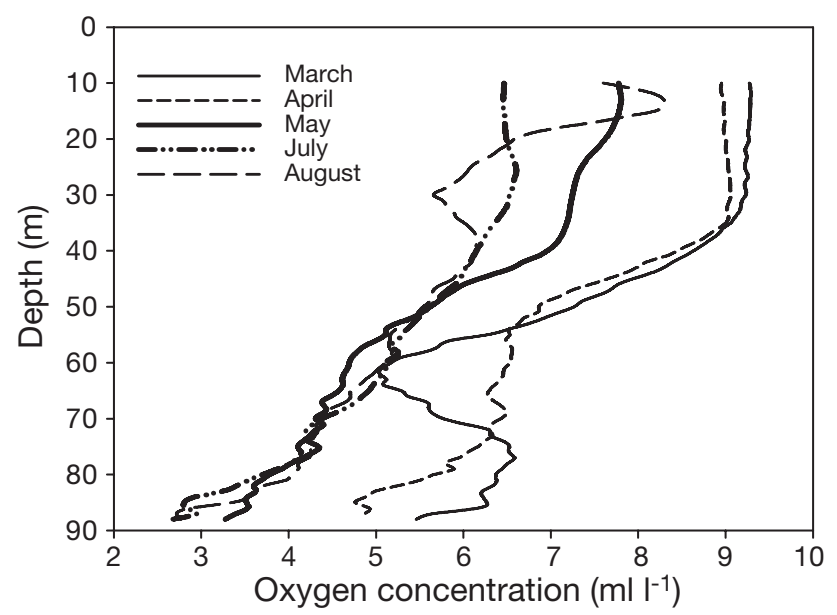

Fig. 7. Sequence of horizontally averaged oxygen profiles in the deep central Bornholm Basin between March and August 2003

\section{DISCUSSION}

The present study quantifies the spatial heterogeneity of the environmental conditions associated with successful spawning by the cod Gadus morhua in the Bornholm Basin. On average, spatial patterns were similar in the second and third quarters, but with overall lower RV thicknesses and less horizontal extension of conditions suitable for egg survival in the third quarter. The observed basin-wide variation in RV thickness and oxygen content inside this volume can result in marked horizontal differences in oxygen-related egg mortality, especially during stagnation years. A clear preference for spawning at locations in the deep basin was evident after both inflow events and in stagnation periods. No preference for spawning in welloxygenated water masses or for specific thermal conditions (not shown) was detectable during either stagnation or inflow years.

Recruitment of Baltic cod critically depends on egg survival (e.g. Köster et al. 2001). Hydrographic conditions in the central and eastern Baltic are critical for successful cod reproduction and the inflow of saline and oxygenated water from the North Sea is a prerequisite for the formation of strong year classes (e.g. Kosior \& Netzel 1989, Bagge et al. 1994). However, to evaluate this hypothesis statistically, it is necessary to quantify the water volume required for successful egg development, which represents a measure of suitable habitat size (Plikshs et al. 1993, MacKenzie et al. 2000). It has been demonstrated that the RV generally declines from spring to summer (MacKenzie et al. 1996), and since the timing of spawning has changed in the past decade from spring to summer (Wieland et al. 2000a) the RV represents the spawning volume correctly only if it is estimated for those times of the year which are relevant for the development of eggs. On the other hand, it has been recognised that RV thickness is not a good measure of oxygen-related egg survival in the Bornholm Basin (Köster et al. 2001), especially when measured only in the deep part of the basin, as was done before the 1990s.

The basic hydrographic processes affecting the environmental conditions for cod egg survival are understood (e.g. Matthäus \& Schincke 1999, Hinrichsen et al. $2002 b)$, but it is not yet possible to predict where and when eggs survive and subsequently generate high recruitment as well (ICES 2004). Such predictions are impossible due to uncertainties in atmospheric forcing conditions and the hydrodynamic responses to these conditions and to biological processes such as the distribution of spawning effort and egg mortality from effects other than hydrography, as well as larval and early juvenile mortality, which complicate the recruitment process. Hydrographic features influence the spatial distribution of the spawning stock (Tomkiewicz et al. 1998) and the vertical distribution of the eggs (Wieland \& Jarre-Teichmann 1997). Potential egg survival depends on the vertical overlap between the eggs and favourable hydrographic conditions (Andersen \& Möllmann 2004). It would therefore be beneficial to take the vertical distributions of eggs into account when egg survival is calculated. However, in the past such measurements were seldom performed because they are technically challenging (e.g. Wieland et al. 2000b).

Direct determination of spawning habitats is often limited by a lack of observations. However, in our example, the applied method of simple quotient rule analysis is based on a large number of surveys, which have provided a considerable number of spatial egg distributions with correspondingly measured environmental data. Hence, our approach enables the characterisation of Baltic cod spawning habitat in terms of different environmental variables. The method provides information about whether the selected environmental variables are randomly related to the spawning locations of Baltic cod or whether they present statistically significant habitat choices. Such characterisation of the spawning habitat of Baltic cod could allow the identification of processes that are likely to alter the size and/or quality of the RV of Baltic cod. Furthermore, spawning habitat size and properties may also be predicted in the absence of biological data (egg or fish abundance) through physical field observations, i.e. the method might be useful to allow regular monitoring of the space-time variability of size and location of the spawning habitat.

The results of our study may improve the understanding of the horizontal movements of Baltic cod in relation to environmental factors and in turn provide 


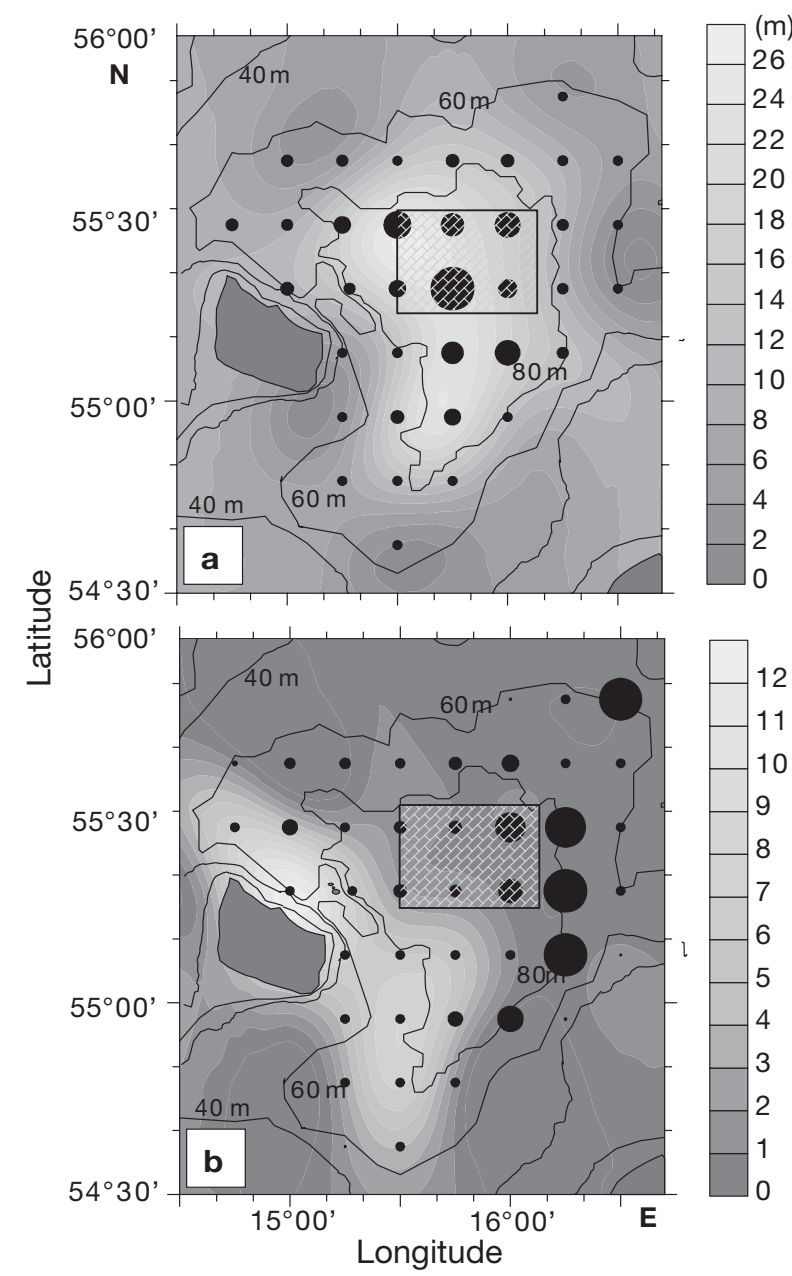

Fig. 8. Gadus morhua. Greys: thickness of Baltic cod reproductive volume $(\mathrm{m})$; dots: Baltic cod Egg Stage Ia distribution $\left(\mathrm{n} \mathrm{m}^{-2}\right.$ ) in the Bornholm Basin: (a) August 1991, (b) August 1999. Rectangle: closed area for all fisheries from 1995 to 2003 during the main spawning season

information on the spatial availability, accessibility and individual vulnerability of cod to fishing activities during spawning. The specific objective of this analysis was to test the hypothesis that patterns of horizontal distribution of cod vary systematically, and that the variation is the consequence of behavioural responses to environmental factors. As a direct application of this approach, our study can be seen as an attempt to characterise the spatial and temporal variability of eastern Baltic cod spawning habitats in light of implementing closed areas to ensure undisturbed spawning. Fig. 8 represents the distribution of the RV and the abundance of the youngest egg stage in August 1991 and 1999. In 1991, a high horizontal overlap between the RV and egg abundance was observed. In 1999, the highest RV was encountered in the northwestern part of the basin near the island Bornholm, while the main egg abundance was recorded in less favourable spawning environments at the eastern edge of the basin. The rectangle superimposed onto Fig. 8 represents the area of the fishing closure from 1995 to 2003 during the main spawning season. If such an area had been closed in August 1991, it would have protected most of the spawning fish from the fishery. On the other hand, in August 1999 neither the horizontal distribution of the layer where spawning was identified as successful nor the horizontal distribution of cod eggs corresponded to the closed area. Setting up temporally and spatially closed areas is considered an efficient management measure to protecting vulnerable fish stocks and key habitats (ICES 2004). Protected areas are set up in zones and at times corresponding to specific features, such as sensitive habitats, large concentrations of a species to be protected, easy identification, or easy controllability. Although their theoretical benefits are often well identified, only little empirical evidence exists to demonstrate their real effectiveness because proper monitoring and assessment requires detailed information that in many cases is scarce or unavailable. Similarly, the inter-annual variability in the distribution pattern of the spawners and surviving egg production of eastern Baltic cod make it difficult to define an appropriate closed area within the Bornholm Basin as the area currently most important for Baltic cod spawning (Tomkiewicz et al. 1998). Although spatial egg distributions did not necessarily match the best environmental conditions and because pronounced RVs outside the central basin are not utilised for intensive spawning, our study indicates that closures should target the deepest parts of the basins presently important for the successful development and mortality of Baltic cod. The presently enforced closed area has been enlarged and now covers more of the central Bornholm Basin, but the northwestern and the southern parts of the central basin, with water depths $>80 \mathrm{~m}$, are still unprotected.

Acknowledgements. We thank all the people involved in sampling and analysing the material. The study was carried out with financial support from the Commission of the European Communities, Agriculture and Fisheries (FAIR), specific RTD-programme CT98 3959 (STORE) as a contribution to EU FP6, TP 8.8 Specific Targeted Research Project 513670 (PROTECT) and the Baltic Sea Region INTERREG III B Neighbourhood Programme BALANCE. This paper does not necessarily reflect the view of the commission.

\section{LITERATURE CITED}

Andersen KH, Möllmann C (2004) Process oriented model of egg mortality for Central Baltic cod, Gadus morhua callarias L. ICES Comm Meet 2004/P:25

Bagge O, Thurow F, Steffensen E, Bray J (1994) The Baltic cod. Dana 10:1-28 
Bretherton FP, Davis RE, Fandry CB (1976) A technique for objective analysis and design of oceanographic experiments applied to MODE-73. Deep-Sea Res 23:559-582

Elmgren R (1984) Trophic dynamics in the enclosed, brackish Baltic Sea. Rapp P-V Reun Cons Int Explor Mer 183: 152-169

Hinrichsen HH, Möllmann C, Voss R, Köster FW, Kornilovs G (2002a) Biophysical modeling of larval Baltic cod (Gadus morhua) growth and survival. Can J Fish Aquat Sci 59(12): 1858-1873

Hinrichsen $\mathrm{HH}$, St. John M, Lehmann A, MacKenzie BR, Köster FW (2002b) Resolving the impact of short-term variations in physical processes impacting on the spawning environment of eastern Baltic cod: application of a 3-D hydrodynamic model. J Mar Syst 32:281-294

ICES (International Council for the Exploration of the Sea) (1999) Report of the ICES Baltic Fisheries Assessment Working Group. ICES Comm Meet 1999/ACFM:15

ICES (International Council for the Exploration of the Sea) (2004) Report of the study group on closed spawning areas of eastern Baltic cod. ICES Comm Meet 2004/ACFM:17

ICES (International Council for the Exploration of the Sea) (2005) Spawning and life history information for the North Atlantic cod stocks. In: Brander K (ed) ICES Cooperative Research Report No. 274, ICES, Copenhagen, p 1-152

Kändler R (1949) Die Häufigkeit pelagischer Fischeier in der Ostsee als Maßstab für die $\mathrm{Zu}$ - und Abnahme der Fischbestände. Kieler Meeresforsch 6:73-89

Kosior M, Netzel J (1989) Eastern Baltic cod stocks and environmental conditions. Rapp P-V Reun Cons Int Explor Mer 190:159-162

Köster FW, Hinrichsen HH, St. John M, Schnack D, MacKenzie BR, Tomkiewicz J, Plikshs M (2001) Developing Baltic cod recruitment models. II. Incorporation of environmental variability and species interaction. Can J Fish Aquat Sci 58:973-984

Köster FW, Möllmann C, Hinrichsen HH, Wieland K and 10 others (2005) Baltic cod recruitment - the impact of climate variability on key processes. ICES J Mar Sci 62: 1408-1425

Krauss W, Brügge B (1991) Wind-produced water exchange between the deep basins of the Baltic Sea. J Phys Oceanogr 21:373-384

MacKenzie BR, St. John M, Plikshs M, Hinrichsen $H_{H}$, Wieland K (1996) Oceanographic processes influencing seasonal and interannual variability in cod spawning habitat in the eastern Baltic Sea. ICES Comm Meet 1996/J:4

MacKenzie BR, Hinrichsen $\mathrm{HH}$, Plikshs $\mathrm{M}$, Wieland $\mathrm{K}$, Zezera AS (2000) Quantifying environmental heterogeneity estimating the size of habitat for successful cod egg development in the Baltic Sea. Mar Ecol Prog Ser 193:143-156

Editorial responsibility: Howard Browman (Associate Editorin-Chief), Storebø, Norway
Matthäus W, Lass U (1995) The recent salt inflow into the Baltic Sea. J Phys Oceanogr 25:280-286

Matthäus W, Schincke H (1999) The influence of river runoff on deep water conditions of the Baltic Sea. Hydrobiologia 393:1-10

Müller A, Pommeranz T (1984) Vertical distribution of fish eggs in the Bornholm Basin. Proc Baltic Int Symp Early Life History of Fishes and 8th Annual Larval Fish Conference, Vancouver

Nissling A, Westin L (1991) Egg buoyancy of Baltic cod (Gadus morhua) and its implication for cod stock fluctuations in the Baltic. Mar Biol 111:33-35

Nissling A, Kryvi H, Vallin L (1994) Variation of egg buoyancy of Baltic cod Gadus morhua and its implication for egg survival in prevailing conditions in the Baltic Sea. Mar Ecol Prog Ser 110:67-74

Plikshs M, Kalejs M, Grauman G (1993) The influence of environmental conditions and spawning stock size on the yearclass strength of the eastern Baltic cod. ICES Comm Meet $1993 / \mathrm{J}: 22$

Rohlf N (1999) Aktivität und Vertikalwanderung der Larven des Ostseedorsches (Gadus morhua callaris) während der Dottersackphase. Ber Inst Meereskd 321

Tomkiewicz J, Lehmann KM, St. John M (1998) Oceanographic influences on the distribution of Baltic cod (Gadus morhua) during spawning in the Bornholm Basin of the Baltic Sea. Fish Oceanogr 7:35-47

van der Lingen $C D$, Hutchings L, Merkle D, van der Westhuizen JJ, Nelson J (2001) Comparative spawning habitats of anchovy (Engraulis capensis) and sardine (Sardinops sagax) in the southern Benguela upwelling ecosystem. In: Kruse GH, Bez N, Booth T, Dorn M and 6 others (eds) Spatial processes and management of marine populations. University of Alaska Sea Grant, Fairbanks, p 185-209

Wieland K (1995) Einfluss der Hydrographie auf die Vertikalverteilung und Sterblichkeit der Eier des Ostseedorsches (Gadus morhua callarias) im Bornholm Becken, südliche zentrale Ostsee. Ber Inst Meereskd 266

Wieland K, Jarre-Teichmann A (1997) Prediction of vertical distribution and ambient development temperature of Baltic cod, Gadus morhua L, eggs. Fish Oceanogr 6: 172-176

Wieland K, Waller U, Schnack D (1994) Development of Baltic cod eggs at different levels of temperature and oxygen content. Dana 10:163-177

Wieland K, Jarre-Teichmann A, Horbowa K (2000a) Changes in the timing of spawning of Baltic cod: possible causes and implications for recruitment. ICES J Mar Sci 57(2): 452-464

Wieland K, Hinrichsen HH, Grønkjær P (2000b) Stagespecific mortality of Baltic cod (Gadus morhua L.) eggs. J Appl Ichthyol 16:266-272

Submitted: June 29, 2006; Accepted: March 18, 2007

Proofs received from author(s): August 27, 2007 